\title{
CORONAVIRUSES IN POLARIZED EPITHELIAL CELLS
}

\author{
J.W.A. Rossen, ${ }^{1}$ C.P.J. Bekker, ${ }^{1}$ W.F. Voorhout,${ }^{2}$ M.C. Horzinek, ${ }^{1}$ \\ A. Van Der Ende, ${ }^{3}$ G.J.A.M. Strous, ${ }^{3}$ and P.J.M. Rottier ${ }^{1}$ \\ ${ }^{1}$ Institute of Virology \\ ${ }^{2}$ Department of Functional Morphology \\ ${ }^{3}$ Laboratory of Cell Biology \\ Utrecht University \\ Yalelaan 1 \\ 584 CL Utrecht \\ The Netherlands
}

\begin{abstract}
Coronaviruses have a marked tropism for epithelial cells. In this paper the interactions of the porcine transmissible gastroenteritis virus (TGEV) and mouse hepatitis virus (MHV-A59) with epithelial cells are compared. Porcine (LLC-PK1) and murine (mTAL) epithelial cells were grown on permeable supports. By inoculation from the apical or basolateral side both TGEV and MHV-A59 were found to enter the polarized cells only through the apical membrane. The release of newly synthesized TGEV from LLC-PK1 cells occurred preferentially from the apical plasma membrane domain, as evidenced by the accumulation of viral proteins and infectivity in the apical culture fluid. In contrast, MHV was released preferentially from the basolateral membrane of mTAL cells. The apical release of TGEV and the basolateral release of MHV may explain the in vivo establishment of a local and systemic infection, respectively.
\end{abstract}

\section{RESULTS AND DISCUSSION}

Most coronaviruses cause enteric and/or respiratory infections. However, some coronaviruses spread systemically. The basis for these diseases appears to be the marked tropism of most coronaviruses for epithelial cells of the respiratory and intestinal tract. For example, TGEV which causes diarrhoea in pigs, infects intestinal epithelial cells ${ }^{1}$. MHV-A59 spreads systemically. This virus infects epithelial cells of the respiratory tract before being disseminated to other organs ${ }^{2}$. In epithelial plasma membranes two domains can be distinguished, the apical and basolateral, which are separated by tight junctions. In general, virus 


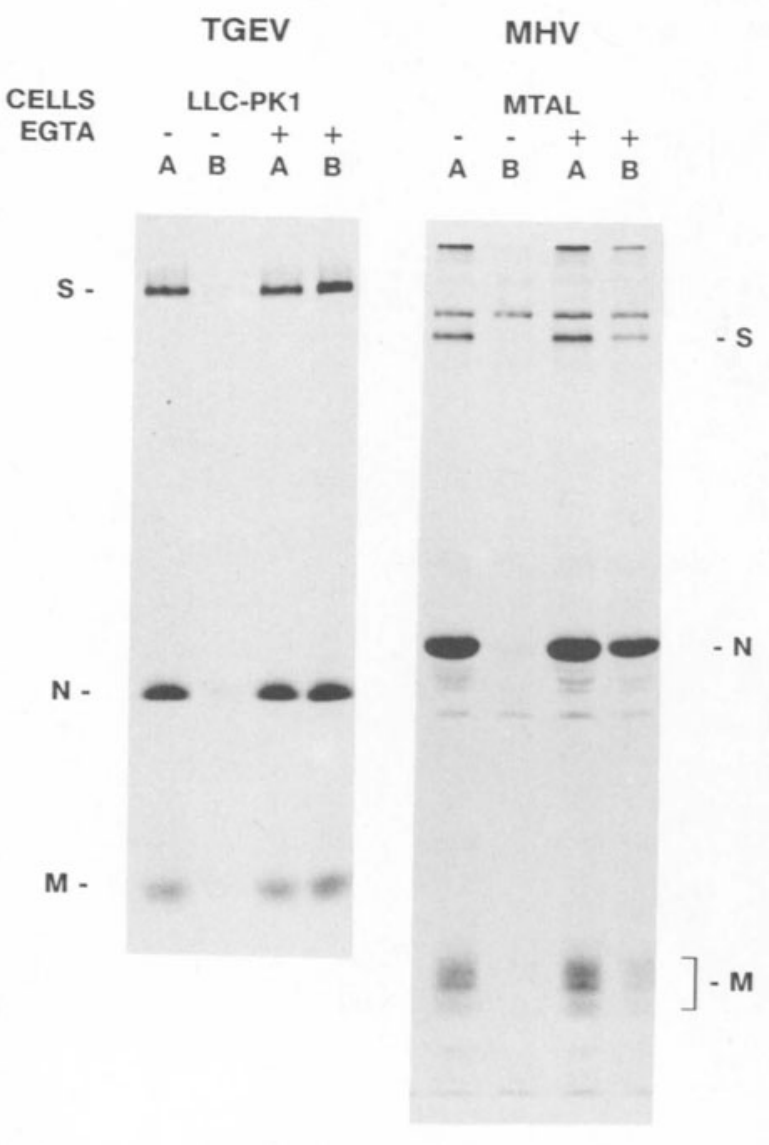

Figure 1. Entry of TGEV and MHV into LLC-PK 1 and mTAL cells. Cells grown on permeable supports were inoculated from the apical (A) or basolateral (B) side with TGEV or MHV, labelled with $100 \mu \mathrm{Ci}{ }^{35}$ S-labelling mix (LLC-PK1:4$6 \mathrm{hpi}$; mTAL: 6-9 hpi) and lysed in lysisbuffer. Subsequently, viral proteins were precipitated from the cell lysates with MHV or TGEV specific antisera and separated in a SDS- $10 \%$ polyacrylamide gel. The position of the spike (S), nucleocapsid (N) and membrane protein (M) are indicated.

entry into and release from epithelial cells are polarized, i.e. restricted to the apical or basolateral domain ${ }^{3}$. In this study we compared the side of TGEV and MHV-A59 entry into and the release of these viruses from polarized porcine LLC-PK1 and murine mTAL cells, respectively. Both cell lines are derived from the proximal tubule of a kidney.

LLC-PK 1 and mTAL cells were grown on permeable supports to have separate access to their apical and basolateral plasma membrane domain. Subsequently, cells were inoculated with TGEV or MHV-A59 from the basolateral or apical side. Cells were labelled with ${ }^{35} \mathrm{~S}$-labelling mix, lysed and viral proteins were precipitated from the lysates with MHV or TGEV specific antisera. Figure 1 shows that the entry of both MHV and TGEV into the epithelial cells is restricted to the apical plasma membrane domain. To exclude the possibility that these findings resulted from the inability of the virus to pass the permeable support and reach the cells, cells were treated with EGTA before infection. This treatment opens the tight junctions between the cells. The cells could now be infected from both sides (Figure 1).

To determine the side of release of TGEV and MHV from these cells, apical and basolateral culture media of infected cells were collected and analyzed for the amount of infectious virus particles. In addition, media of infected, radiolabelled cells were collected and viral proteins were precipitated from these media using the virus specific antisera. Table 1 shows that infectious TGEV particles are preferentially released into the apical medium, whereas infectious MHV particles are preferentially released into the basolateral medium. 
Table 1. Release of infective virus particles from

TGEV-infected LLC-PK1 and MHV-infected MTAL cells into apical and basolateral medium

\begin{tabular}{lccl}
\hline Virus & $\begin{array}{c}\text { Titer } \\
\text { apical }\end{array}$ & $\begin{array}{c}\text { Titer }^{\mathrm{a}} \\
\text { basolateral }\end{array}$ & $\begin{array}{c}\text { Ratio } \\
\text { apical/basolateral }\end{array}$ \\
\hline $\mathrm{TGEV}^{\mathrm{b}}$ & $4.1 \times 10^{6}$ & $1.3 \times 10^{5}$ & 31.5 \\
$\mathrm{MHV}^{\mathrm{c}}$ & $7.1 \times 10^{4}$ & $5.8 \times 10^{5}$ & 0.12 \\
\hline${ }^{\mathrm{a}}$ Mean value of six experiments. & \\
${ }^{\mathrm{b}}$ Titers in plaque forming units. \\
${ }^{{ }^{c} \text { Titers in TCID }}$ - \\
\end{tabular}

These data were confirmed by the results of the immunoprecipitation shown in Figure 2, as TGEV and MHV proteins were predominantly released into the apical and basolateral media, respectively.

In this paper it is shown that both TGEV and MHV enter epithelial cells through the apical side. However, in contrast to the apical release of TGEV, MHV is preferentially released from the basolateral membrane of epithelial cells. The results support the idea that the rapid lateral spread of the TGEV infection over the intestinal epithelia occurs by the preferential release of virus from infected epithelial cells into the gut lumen followed by efficient infection of nearby cells through the apical domain. In addition, the basolateral release of MHV from epithelial cells may be the first step in the establishment of a systemic disease.

Figure 2. Release of TGEV and MHV from LLC-PK1 and MTAL

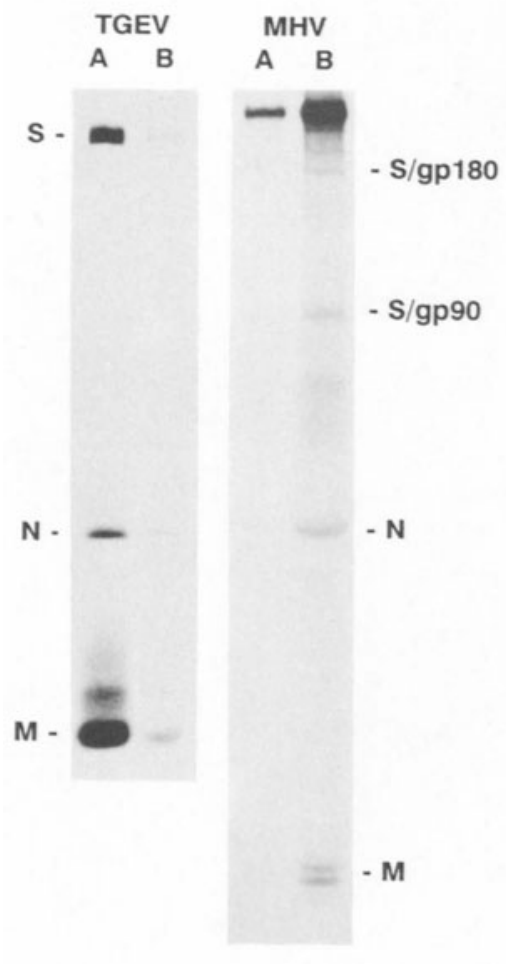
basolateral (B) media using virus specific antisera and separated in a SDS- $10 \%$ polyacrylamide gel. 


\section{REFERENCES}

1 Pensaert, M,E O Haelterman, and E J Hınsman Transmıssıble gastroenterıtıs of swıne virus-intestınal cell interactions 2 Electron microscopy of the epithelium in isolated jejunal loops Arch Gesamte Virusforsh 1990,31 335-351

2 Compton, S R, S W Barthold, and A L Smith The cellular and molecular pathogenesis of coronaviruses Laboratory Anımal Science 1993,43 15-26

3 Tucker, S P, and R W Compans Virus infection of polarized epithelial cells Adv Virus Res $1993,42187-247$ 